\title{
OPPORTUNITY IN ANAESTHESIA, Saint John, N.B.
}

The Region 2 Hospital Corporation is currently seeking an anaesthetist to join its department of 16. The successful candidate will be based in Saint John, New Brunswick.

The Saint John Regional Hospital is an 800 bed accredited tertiary facility which serves as provincial referral centre for several services such as cardiac surgery, neurosurgery and reconstructive plastic surgery. Anaesthesia is provided for all surgical specialities. There is a comprehensive obstetrical analgesia service. The department is also involved in intensive care and pain management.

Saint Joseph's Hospital, Saint John is a 200 bed community hospital. Its future surgical role will be to function as a day surgery and short stay surgery unit. The surgical suite is scheduled for complete renovation for this purpose.

In addition to this varied clinical practice the department is engaged in an active residency training programme affiliated with Dalhousie University. The successful candidate will be eligible for a university appointment.

Saint John serves a population of 125,000 . The beautiful St. John and Kennebecasis Rivers comprise the city's waterways and offer excellent conditions for boating and other outdoor activities. It is a great place to raise a family.

Candidates should be certified by the Royal College of Physicians and Surgeons of Canada. They should be permanently resident in Canada. Post-certification training is preferred (particularly in the areas of cardiac anaesthesia or intensive care).

If you are interested in being considered for this position. I would very much like to hear from you.

\section{INDEX TO ADVERTISERS}

Hoffmann-LaRoche

Janssen Pharmaceutica

North American Dräger

Ohmeda

Organon Canada Ltd.

Puritan-Bennett Canada Ltd.

Wellcome Medical Division/

Burroughs Wellcome Inc.

Zeneca Pharma
(PAGE)

PRESCRIBING INFO. (PAGE)

$\mathrm{XXVI}, \mathrm{XXVII}$ XXII, XXXIII XIV, OUTSIDE BACK COVER ... IV INSIDE BACK COVER .. II XXIV vil NSIDE FRONT COVER VIII, IX, XII, XIII
$\mathrm{XIX}, \mathrm{XX}$ $\mathrm{XXVIII}, \mathrm{XXIX}, \mathrm{XXX}$

Canadian Anaesthetists' Society

CLASSIFIED ADVERTISING

Churchill Livingstone VI, $x, x V, x V I, x X I, x X I I, x X V, x X X I, x x x V$

Classified Advertising and Meetings. $\mathrm{XXXII}$

Ministry of Health of the State of Kuwait

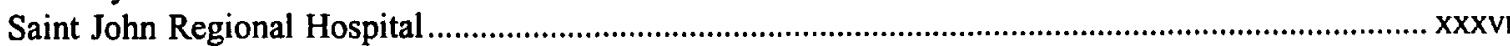

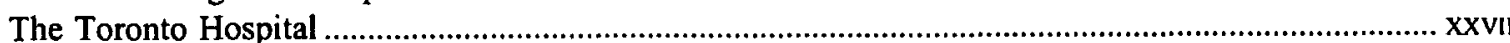

Williams \& Wilkins XXXIV 